\title{
Keanekaragaman Katak di Sekitar Pegunungan Arfak
}

\section{The Diversity of Frogs AROUND the ARFAK MoUntains}

\author{
Isti Indrayani ${ }^{1, *}$, Keliopas Krey ${ }^{2}$, Yance de Fretes ${ }^{3}$ \\ ${ }^{1,2}$ Fakultas Matematika dan Ilmu Pengetahuan Alam Universitas Papua \\ Jl. Gunung Salju, Amban - Manokwari, Indonesia 98314 \\ ${ }^{3}$ Conservation International \\ Jalan Transito Wosi Dalam No. 56 RT 01/RW 13, Lembah Hijau \\ Manokwari, Papua Barat 98312
}

Dikirim: 10 Maret 2020; Disetujui: 13 Juni 2020; Diterbitkan: 29 Juni 2020

Inti Sari

Penelitian ini bertujuan untuk mendokumentasi keanekaragaman spesies katak pada berbagai habitat di sekitar Pegunungan Arfak; perbedaan dan kesamaan spesies antara lokasi penelitian, pengaruh habitat dan suhu terhadap keragaman spesies dan jumlah individu, dan perbandingan spesies dengan lokasi penelitiannya lainnya di Papua Barat, Papua dan Papua New Guinea. Penelitian ini dilaksanakan di Kampung Uyehegbrik (Prafi), Hijou (Neney) dan Anggra (Minyambauw) di Manokwari dan Manokwari Selatan. Katak disampel dengan menggunakan purposive sampling dengan teknik Visual Audio Encouter Survey (VAES) untuk memaksimal pencatatan spesies di tiap lokasi penelitian. Shannon-Weiner Diversity Index ( $\left.\mathrm{H}^{\prime}\right)$ digunakan untuk menghitung species diversity dan $t$-test untuk melihat perbedaan keragaman spesies. Penelitian ini mencatat 15 spesies katak dari 7 famili, empat spesies di antaranya diduga spesies baru. $t$-test menunjukkan ada perbedaan keanekaragaman katak antara lokasi; kebanyakan spesies diamati pada habitat akuatik. Indeks keragaman hayati menunjukkan bahwa keanekaragaman hayati di sekitar Pegunungan Arfak rendah, tetapi besar kemungkinan karena metode penelitian yang digunakan. Perbandingan hasil studi lainnya menunjukkan bahwa 53\% spesies yang dicatat dalam penelitian, tidak tercatat di lokasi penelitiannya.

Kata Kunci: Keanekaragaman Spesies Katak, VAES, Pegunungan Arfak.

\begin{abstract}
This study was designed to document frog diversity at various habitat from around the Arfak Mountain, and examine species similarity between research sites, relationship between habitat and species. Field studies conducted at 3 villages: Uyehegbrik (Prafi District), Hijou (Neney District) and Anggra (Minyabou District). We used purposive sampling with VAES tehniques to sampe all habitats within the study sites. The Shannon -Weiner Diversity Index $\left(H^{\prime}\right)$, student t-test and simple correlation were used for data analysis. About 15 species from 7 families were recorded from all sites, where 4 species are expected to be new species. Uyehegbrik has higher and significant different frog diversity than Hijou and Anggra. This study recorded low to medium frog diversity around the Arfak Mountains, but this may be due to weather and field constraints. Compare to previous studies, about 53\% of species observed during this survey were not recorded.
\end{abstract}

Keywords: Frog Species Diversity, VAES, Arfak Mountains.

\footnotetext{
* Korespondensi Penulis

Telepon : +62 81247235643

Email : istyindrayani30@gmail.com
} 


\section{Pendahuluan}

Provinsi Papua Barat dan Papua diketahui memiliki keanekaragaman hayati dan tingkat endemisitas yang tinggi di Indonesia. Selain memiliki keanekaragaman hayati yang tinggi, daerah ini juga memiliki ekosistem beragam dan alami, dan sebagian besar daratannya masih tertutup hutan. Para ahli taksonomi memperkirakan ada sekitar ribuan spesies di Tanah Papua, dan jumlah ini terus bertambah sejalan dengan meningkatnya kegiatan penelitian. Kelompok herpetofauna (katak dan reptilia), misalnya, terus bertambah sejak kegiatan penelitian lapangan dilaksanakan di Papua sejak tahun 1996 (Mack \& Alonso, 2000). Saat ini, Tanah Papua tercatat memiliki sekitar 450 spesies, di mana 35\% merupakan spesies endemik (Allison, 2007). Namun, jumlah ini masih separuh dari jumlah spesies yang telah didokumentasi di Papua New Guinea. Perbedaan ini disebabkan Papua New Guinea karena lebih banyak melakukan survei keanekaragaman hayati.

Kegiatan konservasi di Papua Barat telah dilaksanakan pemerintah di awal tahun 1980an, dengan menetapkan kawasan konservasi untuk melindungi spesies yang ada serta habitatnya. Ada sekitar 25 kawasan konservasi yang dikelola oleh Pemerintah Pusat lewat Balai Besar Konservasi Sumber Daya Alam (BKSDA) Papua Barat. Hutan Papua Barat masih dalam keadaan alami, karena jumlah penduduk yang terbatas serta sulitnya akses ke daerah-daerah terpencil. Namun sejalan dengan perbaikan situasi politik dan perbaikan kesehatan dalam tiga dekade ini, jumlah penduduk cenderung meningkat, tekanan kepada habitat alam, terutama hutan terus meningkat untuk memenuhi kebutuhan pemukiman, akses ke pasar dan pembangunan infrastruktur lainnya. Pada periode 1990-2018 Provinsi Papua Barat telah kehilangan sekitar 2 juta hektar hutan hujan primer menjadi hutan sekunder atau kawasan non hutan. Hasil prediksi laju perubahan atau pengurangan hutan primer Papua Barat periode 2018-2033 menunjukkan peningkatan sangat mengkhawatirkan (Conservation International, 2020). Fenomena ini dapat dilihat pada daerahdaerah otonomi baru di Provinsi Papua Barat, seperti sekitar Kabupaten Pegunungan Arfak, Kabupaten Manokwari Selatan dan lainnya. Sebagaimana diketahui bahwa kehilangan dan perusakan habitat ini merupakan salah satu ancaman utama kepunahan berbagai spesies yang ada di Papua, terutama taksa endemik atau yang rentan terhadap perubahan habitat, seperti kelompok amfibia.

Memperhatikan uraian di atas, dianggap perlu melakukan penelitian untuk mendokumentasi keanekaragaman spesies katak (amfibia) dan keadaan habitatnya yang ada di sekitar Pegunungan Arfak serta membandingkan dengan keanekaragaman katak berbagai tempat lainnya di Papua Barat dan lainnya. Kawasan Pegunungan Arfak dipilih karena berbagai pertimbangan, antara lain jarak yang relatif dekat dengan Kota Manokwari, mempunyai sejarah penelitian sejak ratusan tahun lalu (termasuk Alfred R. Wallace dan para peneliti Eropa lainnya), juga merupakan salah satu daerah otonomi baru yang sedang gencar membangun infrastruktur jalan, serta berdekatan dengan salah satu kawasan konservasi penting (Cagar Alam Pegunungan Arfak) yang ada di Tanah Papua.

\section{Metode}

\section{A. Lokasi dan Waktu Penelitian}

Penelitian ini dilaksanakan di tiga lokasi (Gambar 1): Kampung Uyehegbrik, Distrik Prafi $\left(0^{\circ} 55^{\prime} 27,2^{\prime \prime} \mathrm{LS}, 133^{\circ} 48^{\prime} 25,7^{\prime \prime}\right.$ BT, dengan ketinggian sekitar $178 \mathrm{~m}$ dpl); Kampung Hiyou, Distrik Neney (126'49,3”LS, $134^{\circ} 0^{\prime} 28^{\prime \prime} \mathrm{BT}$, dengan ketinggian $932 \mathrm{~m} \mathrm{dpl)} \mathrm{dan} \mathrm{Kampung}$ Anggra, Distrik Minyambouw (1 ${ }^{\circ} 8^{\prime} 9,4^{\prime \prime} \mathrm{LS}$, 13353'1"BT, sekitar $1570 \mathrm{~m} \mathrm{dpl}$ ). Penelitian lapangan dilaksanakan pada tanggal 21 Juli - 1 Agustus 2019. 


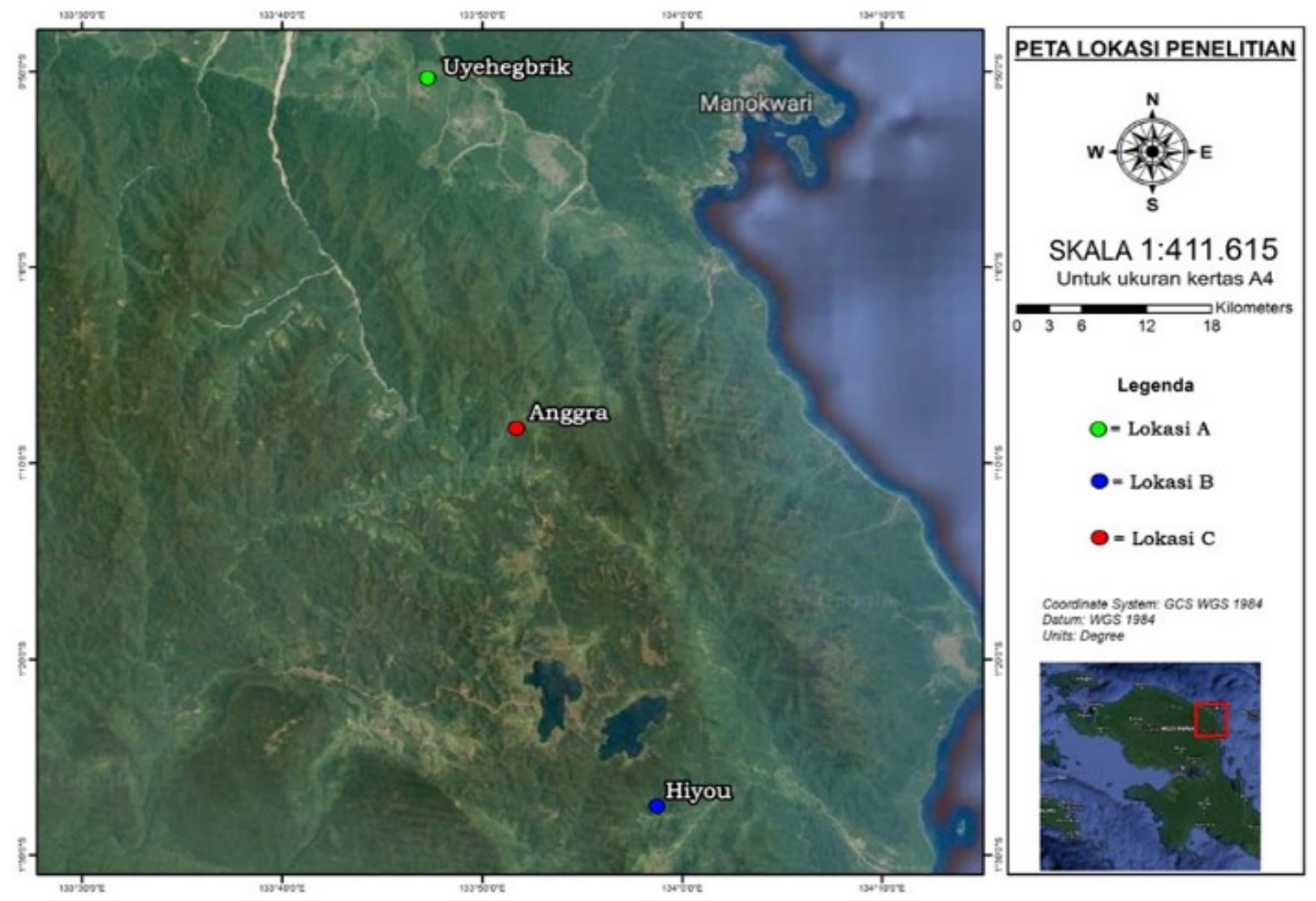

Gambar 1. Lokasi Penelitian Katak di sekitar Pegunungan Arfak

\section{B. Pengambilan Sampel dan Analisa Data}

Penelitian ini menggunakan metode VAES

(Visual Audio Encounter Surveys) (Crump \& Scott Jr., 1994) dengan purposive sampling, di mana katak disampel di semua habitat yang berada di lokasi penelitian. Pengambilan sampel dan observasi dilaksanakan jam 19:0021:00 oleh 3-5 orang. Informasi yang dicatat adalah spesies yang diamati, koordinat, suhu dan kelembaban. Semua spesies yang dijumpai difoto dengan high resolution (piksel yang tinggi); spesies yang unik atau jarang dijumpai dibuat spesimen jaringan dan individu untuk proses identifikasi lanjutan dan disimpan di Laboratorium Biologi, Fakultas Ilmu Pengetahuan Alam, Universitas Papua (Indrayani, 2019).

Identifikasi lapangan menggunakan The Frogs of New Guinea and the Solomon Islands (Menzies, 2006) dan Field Guide to Frogs of the Mimika Region-Papua, Indonesia (Richards,
2015), dan bantuan Dr. Stephen Richard dari South Australian Museum. Keragaman spesies pada tiap lokasi dihitung dengan Shannon Diversity Index.

$$
\left(H^{\prime}\right):-\Sigma p i \ln p i ; p i=n i / N
$$

di mana:

$H^{\prime}=$ Shannon-Wiener Diversity Index (Indeks Keragaman Shannon-Wiener)

$n i=$ Jumlah individu dari spesies tersebut (kei) seluruh jenis

$\ln$ = Logaritma natural

$N=$ Jumlah total individu dari seluruh jenis

Untuk menghitung Indeks kemerataan (evenness) (Magurran, 1988) menggunakan rumus: 


$$
E=\frac{H^{\prime}}{\ln S}
$$

di mana:

$E$ = Indeks kemerataan jenis

$H^{\prime}=$ Indeks Keragaman Shannon-Wiener

$S=$ Jumlah spesies

Nilai $E$ berkisar antara $0-1$, di mana nilai mendekati 0 menandakan tingkat kemerataan yang rendah dan nilai mendekati 1 menunjukkan tingkat kemerataan yang tinggi.

Untuk menghitung Indeks kelimpahan relatif spesies katak dihitung menggunakan rumus:

$$
K R=\frac{n i}{N} \times 100 \%
$$

di mana:

$K R=$ Kelimpahan Relatif

$n i=$ Jumlah individu spesies ke $i$

$N=$ Jumlah individu seluruh spesies

Perhitungan species diversity dan perbandingan keragaman pada tiap lokasi menggunakan t-test dengan menggunakan Shannon Diversity t-test Calculator, yang dibuat dalam Excel (Gardener, 2017).

Untuk melihat perbedaan atau kesamaan spesies di antara lokasi penelitian digunakan Sorensen Similarity Coefficient (Krebs, 1989) dengan rumus:

$$
S_{s}=2 a / 2 a+b+c
$$

di mana:

$S_{s}=$ Sorensen Similiarity Coefficient

$a=$ Jumlah spesies amfibi yang terdapat di lokasi penelitian $a$ dan $b$

$b=$ Jumlah spesies amfibi yang terdapat di lokasi penelitian $b$

$c=$ Jumlah spesies amfibi yang terdapat di lokasi penelitian $a$
Nilai Sorensen Similarity berkisar antara 0, di mana nilai yang mendekati 1 menunjukkan tingkat kesamaan yang tinggi (similar).

\section{Hasil dan Pembahasan}

Total 15 spesies katak dari tujuh famili berhasil diamati dan diidentifikasi dalam penelitian ini (Tabel 1). Tercatat di Kampung Uyehegbrik 8 spesies dengan 124 individu; Kampung Hijou 5 spesies dengan 55 individu dan Kampung Anggra, 5 spesies dan 79 individu.

Gambar 2 menunjukkan kurva spesies (species area curve) untuk melihat usaha pengambilan sampel dan jumlah spesies yang diamati. Gambar ini menunjukkan bahwa sebagian besar spesies di Kampung Uyehegbrik telah berhasil diamati, sedangkan Kampung Hijou dan Anggra masih belum.

Indeks keanekaragaman katak pada 3 lokasi penelitian menunjukkan Uyehegbrik memiliki keragaman jenis katak yang paling tinggi $\left(H^{\prime}: 1,67\right)$ di antara Hijou $\left(H^{\prime}: 1,02\right)$, dan Anggra ( $\left.H^{\prime}: 0,97\right)$; dengan demikian pada disimpulkan bahwa keragaman jenis 3 lokasi penelitian tergolong rendah sampai sedang, jika menggunakan kriteria Odum (1993) yaitu jika $H^{\prime}<1$ berarti keanekaragaman rendah, $H^{\prime} 1$ - 3 berarti keanekaragaman sedang, dan $H^{\prime}>3$ berarti keanekaragaman tinggi.

Gambar 4 menunjukkan hasil perbandingan Indeks Keragaman ShannonWiener yang dihitung dengan Hutcheson t-test (Gardener, 2017) antara lokasi penelitian. Tidak ada perbedaan signifikan antara Hijou dan Anggra, namun ada perbedaan signifikan antara Uyehegbrik dan Hijou, serta antara Uyehegbrik dan Anggra.

Gambar 5 menyajikan perbandingan kemerataan (evenness) antara lokasi penelitian. Uyehegbrik memiliki kemerataan paling tinggi $(E: 0,73)$, dan tinggi untuk Hijou $(E: 0,6,3)$ dan Anggra (E: 0,63).

Tabel 2 menunjukkan hasil perbandingan Indeks Kesamaan Spesies (Sorensen Similarity 
Tabel 1.

Daftar Spesies dan Jumlah Individu Katak

\begin{tabular}{|c|c|c|c|c|}
\hline Famili & Spesies & KU & KH & KA \\
\hline Bufonidae & $\begin{array}{l}\text { Duttaphrynus } \\
\text { melanostictus }\end{array}$ & 7 & - & - \\
\hline Ceratobatrachidae & Platymantis papuensis & 27 & - & - \\
\hline Dicroglossidae & Fejevarya crancrivora & 24 & - & - \\
\hline Dicroglossidae & Limnonectes sp. 1 & 1 & - & - \\
\hline Hilydae & Litoria infrafrenata & 9 & - & - \\
\hline Hilydae & Litoria arfakiana & - & 26 & 47 \\
\hline Hilydae & Litoria cf arfakiana & - & 24 & 25 \\
\hline Hilydae & Litoria cf scaba/rivicola & - & 3 & - \\
\hline Hilydae & Litoria sp. 1 & - & - & 4 \\
\hline Hilydae & Litoria sp. 2 & - & - & 2 \\
\hline Hilydae & Nyctimystes cf pulcher & - & 1 & - \\
\hline Microhylidae & Cophixalus sp. 1 & 46 & - & - \\
\hline Ranidae & Papurana arfaki & 5 & - & - \\
\hline Ranidae & Papurana grisea & 5 & - & - \\
\hline Ranidae & Papurana cf grisea & - & 1 & 1 \\
\hline Jumlah spesies & 15 & 8 & 5 & 5 \\
\hline Jumlah individu & & 124 & 55 & 79 \\
\hline
\end{tabular}

Keterangan:

KU: Kampung Uyehegbrik

KH: Kampung Hiyou

KA: Kampung Anggra

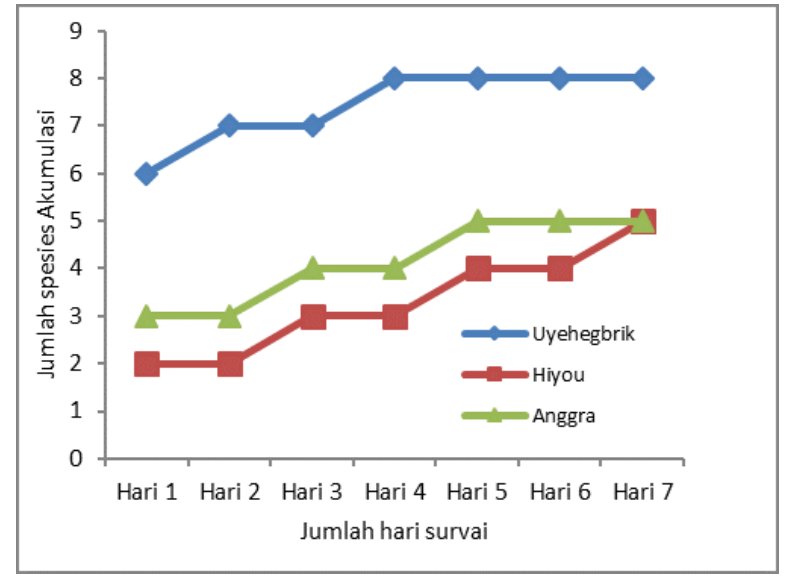

Gambar 2. Kurva Spesies

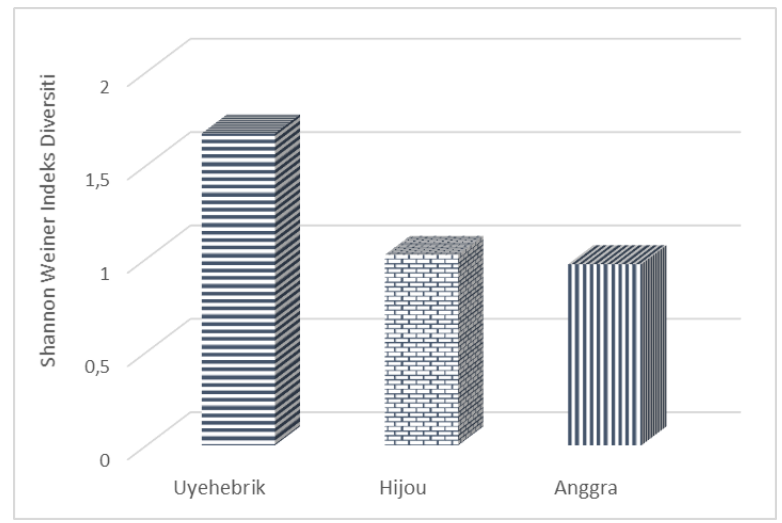

Gambar 3. Indeks Keragaman Shannon-Weiner 

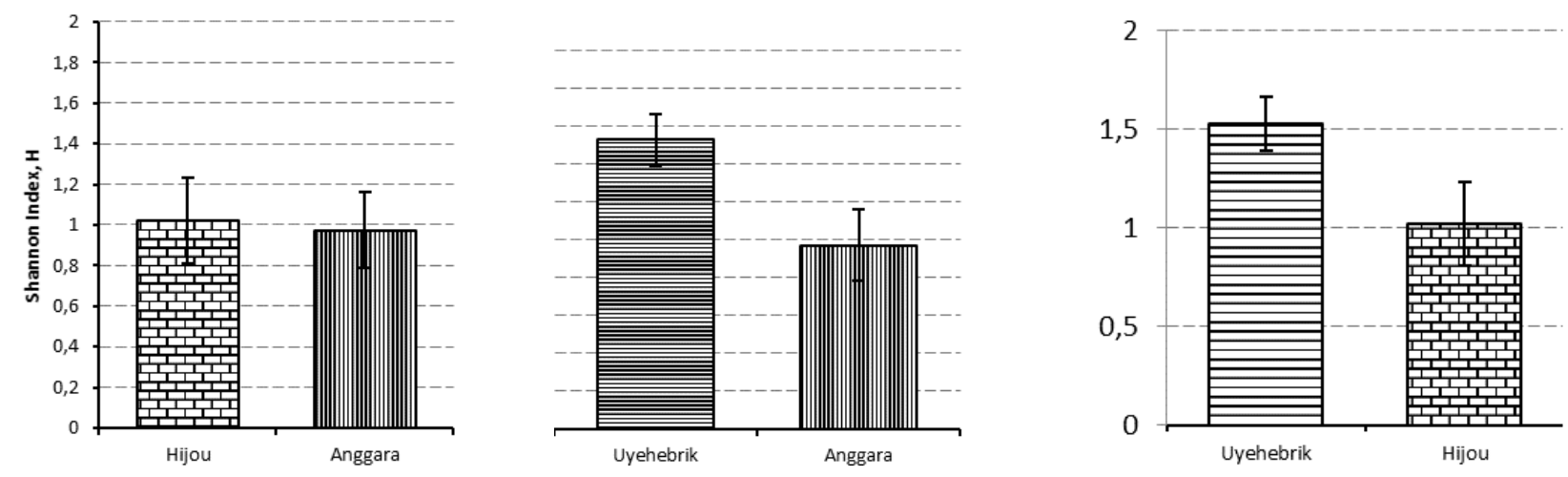

Gambar 4. Perbandingan Indeks Keragaman Shannon-Wiener antara Lokasi Penelitian

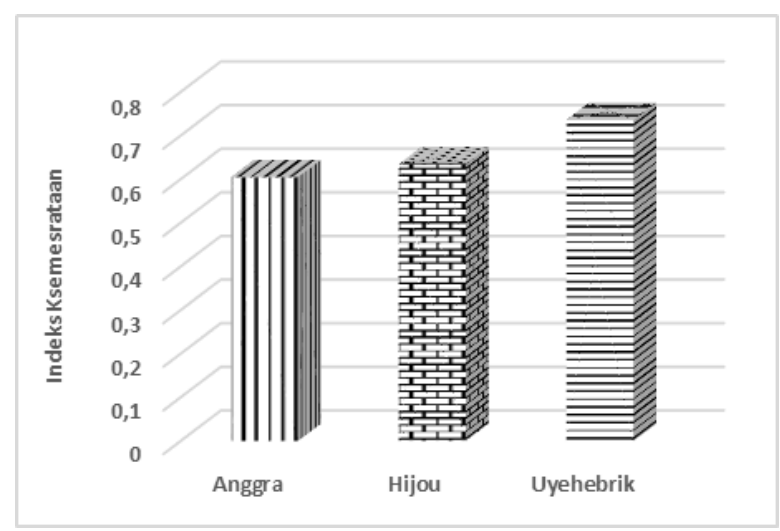

Gambar 5. Indeks Kemerataan Jenis pada Lokasi Penelitian

Coefficient) antara lokasi penelitian. Ada kesamaan yang tinggi antara spesies di Hijou dan Anggra. Ini diduga akibat ada kesamaan ketinggian (altitude) antara dua lokasi penelitian ini dibandingkan dengan Uyehegbrik.

Analisa kelimpahan setiap spesies menunjukkan bahwa katak Litoria arfakiana spesies yang melimpah di Hijou dan Anggra dan Cophixalus sp. di Uyehegbrik (Gambar 6). Fejevarya crancrivora, Limnonectes sp. 1, Papuarana arfaki, Papuarana grisea hanya diwakili oleh 1 individu di Uyehegbrik; dan Nyctimystes cf pulcher, Litoria cf scaba/rivicola, Papuarana cf grisea, Litoria sp. 1 dan Litoria sp. 2 di Hijou dan Anggra.

Gambar 7 menunjukkan bahwa akuatik merupakan habitat yang paling banyak dimanfaatkan oleh spesies katak dalam penelitian.
Tabel 2.

Kesamaan Spesies antara Lokasi Penelitian

\begin{tabular}{lccc} 
& Uyehegbrik & Hijou & Anggra \\
\hline Uyehegbrik & 1 & 0,133 & 0,133 \\
\hline Hijou & & 1 & 0,6 \\
\hline Anggra & & & 1 \\
\hline
\end{tabular}

Hasil penelitian terdapat 3 tipe habitat utama yaitu arboreal, akuatik dan serasa. Tipe habitat yang sering ditemukan spesies katak adalah tipe habitat akuatik karena katak tidak bisa hidup jauh dari habitat akuatik. Hal ini juga disebabkan sebagian besar anura memerlukan habitat akuatik untuk tempat berkembang biak. Kehadiran spesies dan jumlah individu, dipengaruhi oleh faktor lingkungan, salah satu faktor utama adalah suhu (Gambar 8).

Gambar 8a menunjukkan bahwa individu beraksi bervariasi pada keadaan suhu, kebanyakan spesies beraktivitas pada suhu $18-23^{\circ} \mathrm{C}$ (pada dataran tinggi) dan pada 27 $29^{\circ} \mathrm{C}$ (pada dataran rendah); Gambar $8 \mathrm{~b}$ menunjukkan suhu berkorelasi negatif dengan aktivitas katak, yaitu suhu panas maka jumlah spesies atau individu akan menurun. Menurut Duellman \& Trueb (1994) amfibi merupakan jenis satwa eksoterm, di mana suhu tubuhnya sangat bergantung pada suhu lingkungan sekitarnya.

Salah satu kendala dalam "menilai" tingkat keanekaragaman atau keunikan lokasi 


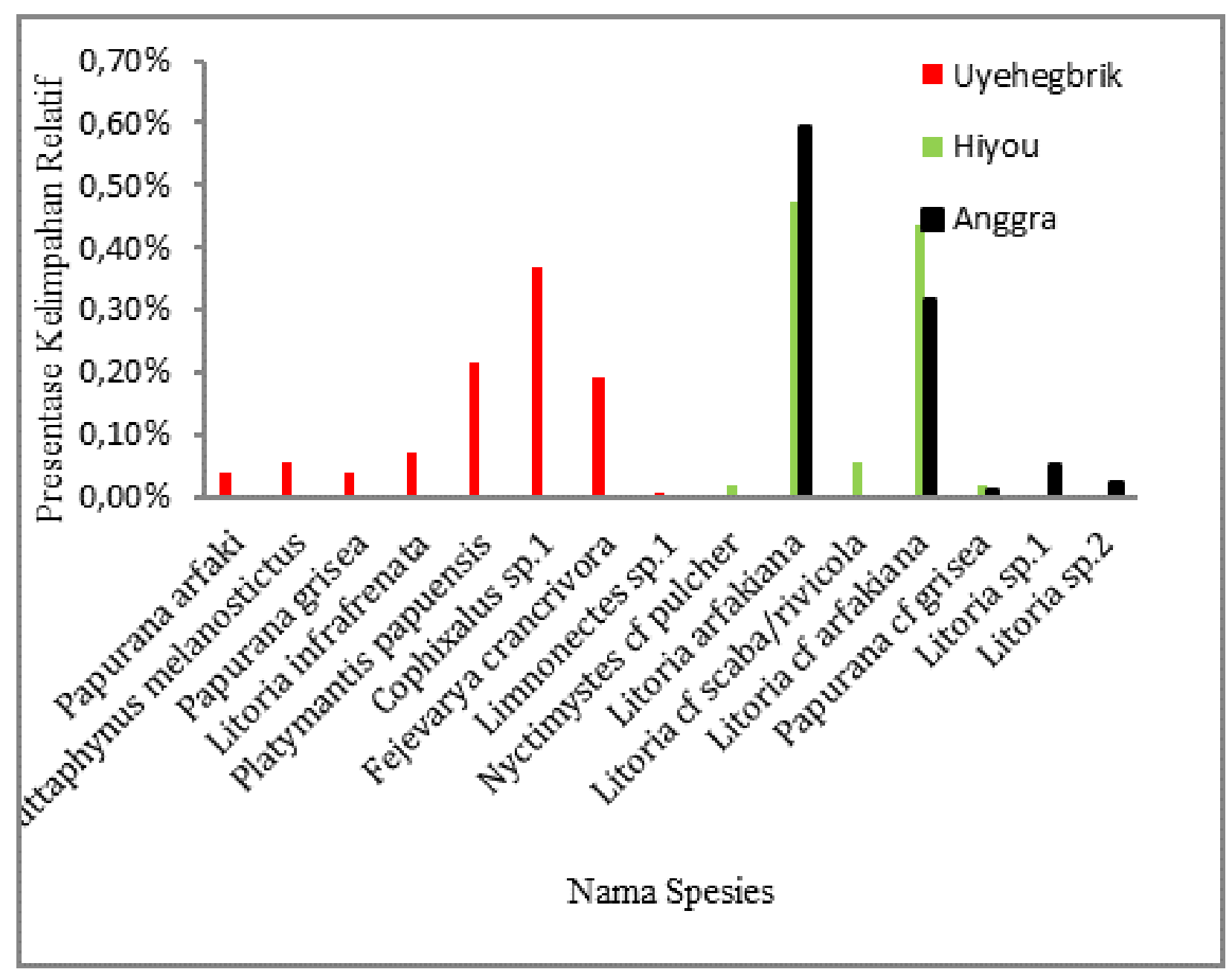

Gambar 6. Kelimpahan Relatif Jenis pada Lokasi Penelitian

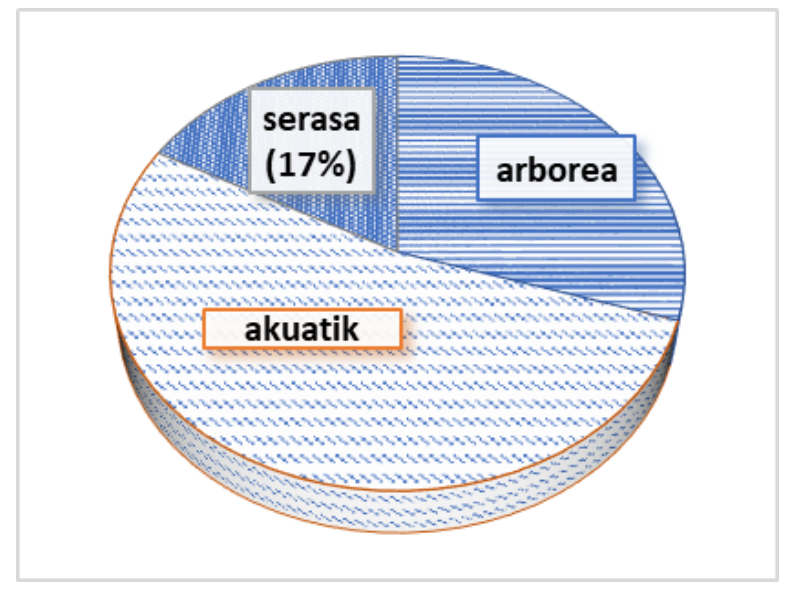

Gambar 7. Habitat Utama Berdasarkan Pengamatan 258 Individu pada 3 Lokasi Penelitian

tertentu adalah masih terbatasnya penelitian dan penyebaran hasil-hasil penelitian serta belum adanya kesepakatan bersama mengenai penggunaan metode pengambilan sampel yang standar (misalnya, dalam penelitian botani) sehingga menyulitkan perbandingan antara lokasi penelitian untuk melihat kesamaan jenis ataupun pola-pola distribusi spesies. Namun demikian, perbandingan spesies antara lokasi penelitian dapat memberikan sedikit gambaran tentang distribusi spesies tertentu. Tulisan ini membandingkan hasil penelitian di sekitar Pegunungan Arfak dengan beberapa lokasi di Papua Barat, Papua dan Papua New Guinea (Huon Peninsula) berdasarkan "kesamaan" lokasi (ketinggian) tempat penelitian.

Krey (2008) melakukan penelitian di Haya, Mamberamo (dataran rendah) dan berhasil mencatat 21 spesies, sementara Beljai \& Worabai (2018) melakukan penelitian di sekitar Pegunungan Arfak dan berhasil 


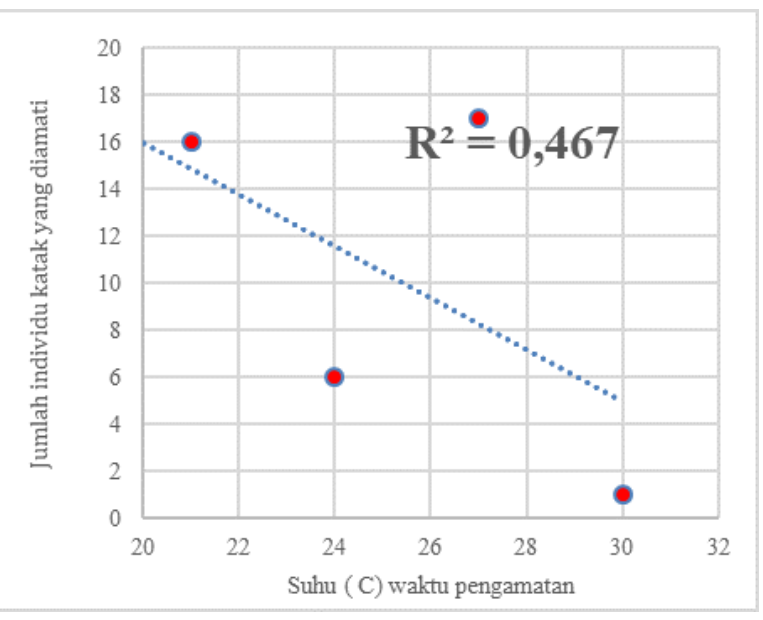

Suhu dan Jumlah Individu

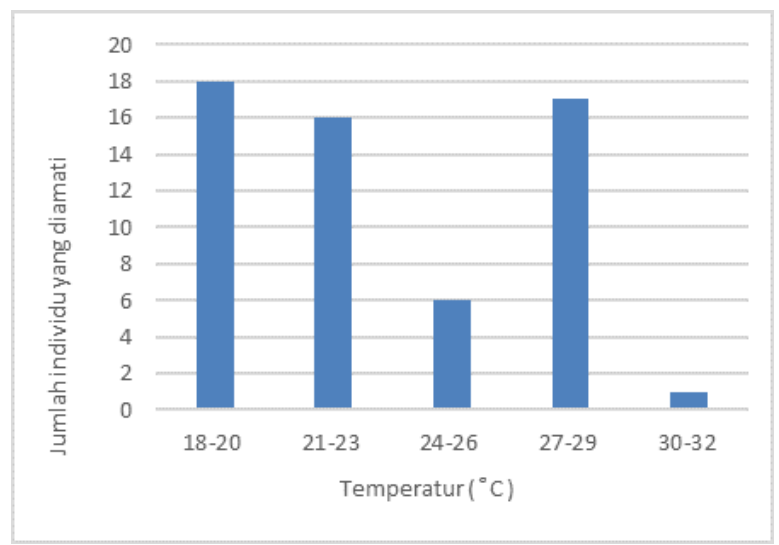

Korelasi antara Suhu dan Jumlah Individu

Gambar 8. Hubungan Antara Suhu dan Keberadaan Spesies dan Individu Katak

Tabel 3.

Spesies Katak Penelitian Saat Ini Dibandingkan dengan Penelitian Lainnya

\begin{tabular}{|c|c|c|c|c|c|c|c|c|c|}
\hline \multirow[b]{2}{*}{ No } & \multirow[b]{2}{*}{ Spesies } & \multirow{2}{*}{$\begin{array}{l}\text { Penelitian } \\
\text { ini }\end{array}$} & \multicolumn{7}{|c|}{ Penelitian lainnya } \\
\hline & & & $\begin{array}{c}\text { Krey } \\
\text { (2008) }\end{array}$ & $\begin{array}{c}\text { Beljai } \\
(2018)\end{array}$ & $\begin{array}{c}\text { Richards } \\
\text { (2000) }\end{array}$ & $\begin{array}{l}\text { Richards } \\
\text { (2000a) }\end{array}$ & $\begin{array}{l}\text { Richards } \\
\text { (2000b) }\end{array}$ & $\begin{array}{l}\text { Zweifel } \\
(1980)\end{array}$ & $\begin{array}{c}\text { Hamadi dkk } \\
\text { (2007) }\end{array}$ \\
\hline 1 & Cophixalus sp.1 & $\sqrt{ }$ & $\sqrt{ }$ & - & & & & & \\
\hline 2 & Duttaphynus melanostictus & $\sqrt{ }$ & - & - & & & & & \\
\hline 3 & Fejevarya crancrivora & $\sqrt{ }$ & - & - & & & & & \\
\hline 4 & Limnonectes sp.1 & $\sqrt{ }$ & - & - & & & & & \\
\hline 5 & Litoria infrafrenata & V & $\bar{v}$ & - & $\sqrt{ }$ & & $\sqrt{ }$ & $\sqrt{ }$ & $\sqrt{ }$ \\
\hline 6 & Litoria arfakiana & $\sqrt{ }$ & - & $\sqrt{ }$ & & & $\sqrt{ }$ & & \\
\hline 7 & Litoria cf arfakiana & $\sqrt{ }$ & - & - & & & & & \\
\hline 8 & Litoria cf scaba/rivicola & $\sqrt{ }$ & - & - & & & & & \\
\hline 9 & Litoria sp.1 & $\sqrt{ }$ & - & - & & & & & \\
\hline 10 & Litoria sp.2 & $\sqrt{ }$ & - & - & & & & & \\
\hline 11 & Nyctimystes cf pulcher & $\sqrt{ }$ & - & - & $\sqrt{ }$ & & & $\sqrt{ }$ & \\
\hline 12 & Papurana arfaki & $\sqrt{ }$ & $\sqrt{ }$ & - & & & $\sqrt{ }$ & & $\sqrt{ }$ \\
\hline 13 & Papuranagrisea & $\sqrt{ }$ & $\sqrt{ }$ & $\sqrt{ }$ & & $\sqrt{ }$ & $\sqrt{ }$ & $\sqrt{ }$ & \\
\hline 14 & Papurana cf grisea & $\sqrt{ }$ & - & - & & & & & \\
\hline 15 & Platymantis papuensis & $\sqrt{ }$ & $\sqrt{ }$ & - & $\sqrt{ }$ & $\sqrt{ }$ & $\sqrt{ }$ & $\sqrt{ }$ & \\
\hline \multicolumn{2}{|c|}{ Jumlah spesis yang dicatat } & 15 & 21 & 5 & 47 & 8 & 21 & 38 & 12 \\
\hline \multicolumn{2}{|c|}{ Jumlah spesies yang sama } & & 5 & 2 & 3 & 3 & 5 & 4 & 2 \\
\hline
\end{tabular}

mencatat 5 spesies. S. Richards et al. (2000) yang ikut serta dalam Rapid Assessment Program (RAP) di Sungai dan Pegunungan Wapoga (dataran rendah dan pegunungan), berhasil mencatat sekitar 47 spesies katak (namun sebagian besar belum dapat diidentifikasi). S. Richards et al. (2002; 2002) ikut dalam RAP Yemang, Yongsu dan mencatat sekitar 8 spesies; dan di Mamberamo (Sungai Tiri, Sungai Furu, dan sekitar Dabra) berhasil mencatat 21 spesies dalam 21 hari. Hamidy \&
Mulyadi (2007) melakukan ekspedisi ke Pulau Waigeo dan berhasil mencatat 12 spesies katak; dan Zweifel (1980) yang ikut dalam The Archbold Expedition di Huon Peninsula (ketinggian 300-4000 m dpl), Papua New Guinea berhasil mencatat sekitar 38 spesies katak.

Tabel 3 menunjukkan ada 3 spesies Litoria infrafrenata, Papurana gresia dan Platymantis papuensis memiliki penyebaran yang luas. Pengamatan Nyctimystes pulcher di 
Pengunungan Arfak merupakan informasi terbaru mengenai distribusi spesies ini (new record). Tabel 5 juga menunjukkan bahwa dua introduksi spesies Duttaphynus melanostictus dan Fejevarya crancrivora diamati di lokasi penelitian ini di Pegunungan Arfak (Kampung Uyehegbrik, Distrik Prafi), tetapi belum ada di lokasi penelitian lainnya. D. melanostictus juga dijumpai dalam jumlah banyak di Kampung Anggra (1.600 m dpl). Menurut penuturan masyarakat di Anggra, spesies ini sengaja dibawa untuk praktikum Biologi.

Penelitian menunjukkan bahwa walaupun ada beberapa spesies yang sama di lokasi penelitian lain (Wapoga 3 spesies, Huon 4 spesies, Haya 5 spesies, Mamberamo 5 spesies, Yemang 3 spesies, dan Waigeo 2 spesies); tetapi sebagian besar (8 spesies atau 53\%) di Pegunungan Arfak tidak diamati di lokasi penelitian lain. Perlu penelitian lebih lanjut untuk menentukan kepastian jenis Litoria of arfakina dan Litoria scaba/rivicola, diduga kuat spesies merupakan spesies yang baru.

\section{Kesimpulan}

Hasil penelitian menyimpulkan bahwa keragaman katak di sekitar Pegunungan Arfak masih terbilang rendah sampai sedang; kemungkinan besar disebabkan faktor metode penelitian (waktu dan tenaga lapangan) serta berbagai kendala logistik lainnya. Namun, hampir sebagian besar spesies yang diamati di dataran rendah (Uyehegbrik) tidak tercatat di lokasi pegunungan (Hijou dan Anggra). Jumlah spesies yang berhasil diamati selama penelitian ini tidak berbeda jauh dengan hasil-hasil penelitian lainnya. Walaupun perbandingan langsung tidak dapat dilaksanakan, karena metode penelitian yang berbeda, tetapi sebagian besar $(53 \%)$ spesies yang diamati dalam tiga lokasi penelitian ini, tidak tercatat dalam penelitian-penelitian lainnya, baik di Provinsi Papua Barat, Papua dan Negara Papua New Guinea, menunjukkan bahwa spesies katak di sekitar Pegunungan "berbeda" dengan di lokasi penelitiannya.

\section{Ucapan Terima Kasih}

Terima kasih kami sampaikan pada masyarakat dan pemerintah di Uyehegbrik, Hijou dan Anggra yang telah mengizinkan dan membantu penelitian di lapangan. Terima kasih khususnya kepada Stephen Richards dari South Australian Museum, Australia, yang membantu dalam pelatihan dan identifikasi; PT Freeport yang membantu Pelatihan Survei Cepat Odonata dan Herpet; Pak Iwan dan Conservation International-Papua Program yang membantu dengan logistik selama penelitian ini. Terima kasih juga kepada para editor anonim yang sudah me-review dan memberikan saran perbaikan naskah tulisan ini.

\section{Referensi}

Allison, A. (2007). Introduction to the Fauna of Papua. In A. J. Marshall \& B. M. Beehler (Eds.), The Ecology of Papua, Part One: Vol. VI (pp. 479-494). Periplus Editions.

Beljai, M., \& Worabai, M. S. (2018). Struktur dan Komposisi Vegetasi Serta Keanekaragaman Jenis Amfibi di Hutan Pegunungan Arfak, Papua Barat. Prosiding Seminar Nasional Masyarakat Biodiversitas Indonesia, 4(1), 1-12. https://smujo.id/psnmbi/article/view/ 2627

Conservation International. (2020). Model Prediksi Perubahan Tutupan Hutan Provinsi Papua Barat.

Crump, M. L., \& Scott Jr., N. J. (1994). Visual encounter surveys. In W. R. Heyer, M. A. Donnelly, R. W. McDiarmid, L. C. Hayek, \& M. S. Foster (Eds.), Measuring and monitoring biological diversity: Standard methods for amphibians. Smithsonian Institution Press.

Duellman, W. E., \& Trueb, L. (1994). Biology of Amphibians. JHU Press.

Gardener, M. (2017). Statistics for Ecologists Using $R$ and Excel: Data Collection, 
Exploration, Analysis and Presentation (2nd ed.). Pelagic Publishing Ltd.

Hamidy, A., \& Mulyadi. (2007). Herpetofauna di Pulau Waigeo. LIPI.

Indrayani, I. (2019). Keanekaragaman Spesies Katak (Amphibi) di Sekitar Pegunungan Arfak. Universitas Papua.

Krebs, C. J. (1989). Ecological Methodology (2nd ed.). Harper \& Row.

Krey, K. (2008). Herpetofauna di Hutan Dataran Rendah Haya, Mamberamo, Papua. Jurnal Natural, 7(1).

Mack, A. L., \& Alonso, L. E. (Eds.). (2000). A Biological Assessment of the Wapoga River Area of Northwestern Irian Jaya, Indonesia. Conservation International.

Magurran, A. E. (1988). Ecological Diversity and Its Measurement. Princeton University Press.

Menzies, J. I. (2006). The Frogs of New Guinea and the Solomon Islands. Pensoft.

Odum, E. P. (1993). Dasar-dasar Ekologi (3rd ed.). Gadjah Mada University Press.

Richards, S., Iskandar, D. T., \& Allison, A. (2000). Amphibians and Reptiles of the Wapoga River Area, Irian Jaya, Indonesia. In A. L. Mack \& L. El Alonso (Eds.), A Biological Assessment of the Wapoga River Area of
Northwestern Irian Jaya, Indonesia (Vol. 14). Conservation International.

Richards, S., Iskandar, D. T., \& Tjaturadi, B. (2002). Amphibians and Reptiles of the Dabra Area, Mamberamo River Basin, Papua, Indonesia. In S. J. Richards \& S. Suryadi (Eds.), A Biodiversity Assessment of the Yongsu-Cyclops Mountains and the Southern Mamberamo Basin, Papua, Indonesia (Vol. 25, pp. 76-79). Conservation International.

Richards, S., Iskandar, D. T., Tjaturadi, B., \& Krishar, A. (2002). Amphibians and Reptiles of the Yongsu Area, Papua, Indonesia. In S. J. Richards \& S. Suryadi (Eds.), A Biodiversity Assessment of the Yongsu-Cyclops Mountains and the Southern Mamberamo Basin, Papua, Indonesia (Vol. 25, pp. 73-75). Conservation International.

Richards, S. J. (2015). Field Guide to Frogs of the Mimika Region, Papua, Indonesia. PT Freeport Indonesia.

Zweifel, R. G. (1980). Results of the Archbold Expeditions No. 103 Frogs and Lizards from the Huon Peninsula, Papua New Guinea. Bulletin of the American Museum of Natural History, 165, 387-434. http:// hdl.handle.net/2246/1047 